\title{
Valved holding chambers (VHCs) for use with pressurised metered-dose inhalers (pMDIs): a review of causes of inconsistent medication delivery
}

\section{*Jolyon P Mitchella, Mark W Nagel ${ }^{b}$}

a Director of Scientific Affairs, Trudell Medical International, London, Canada

${ }^{\mathrm{b}}$ Laboratory Manager, Trudell Medical International

Received 15th January 2007; accepted 26th March 2007

\begin{abstract}
Background: Valved holding chambers (VHCs) are prescribed with pressurised metered-dose inhalers (pMDIs) to improve medication delivery for the treatment of respiratory diseases because they reduce the need for the patient to co-ordinate inhaler actuation with the onset of inhalation. Although mechanically robust and clinically effective if properly designed and pre-conditioned, there are several causes of inconsistent medication delivery if this is not the case. These include: electrostatic charge; incorrect operation of inhalation and exhalation valves; and the fit of the facemask - where present - to the face. In addition, behavioral factors, such as not following patient instructions for use and maintenance, and imperfect breathing technique, amplify overall variability. Aids such as valve movement indicators that provide patient feedback are helpful in order to minimise these factors.

Methods: This article reviews recent literature concerning the causes of inconsistent drug delivery and the improvements that have been made by manufacturers to VHC devices, and assesses the clinical implications. The attributes of a well-designed VHC are summarised.

(C) 2007 General Practice Airways Group. All rights reserved.

JP Mitchell and MW Nagel. Prim Care Resp J 2007; 16(4): 207-214.

doi:10.3132/pcrj.2007.00034
\end{abstract}

Keyw ords asthma, COPD, inhalation therapy, holding chamber

\section{Contents}

Introduction

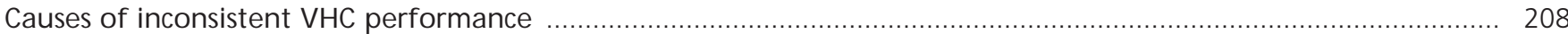

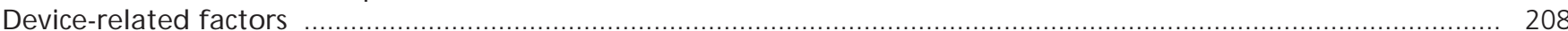

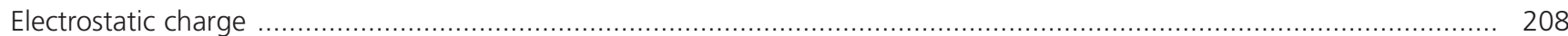

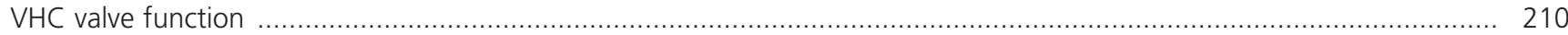

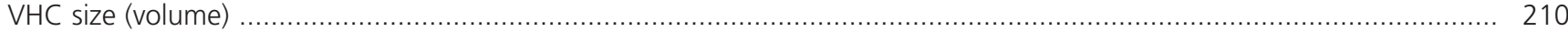

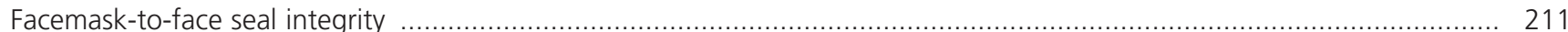

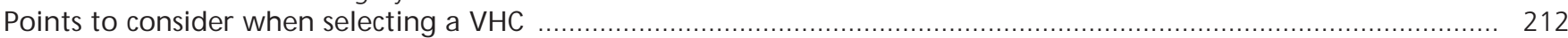

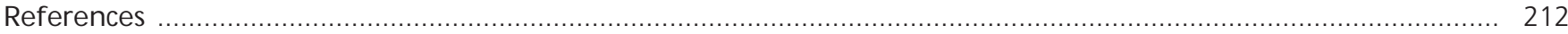

\section{Introduction}

Aerosol-based drug therapy is recognised as an effective modality for managing obstructive respiratory conditions such as asthma ${ }^{1,2}$ and chronic obstructive pulmonary disease (COPD). ${ }^{3,4}$ Pressurised metered-dose inhalers (pMDIs) are widely prescribed for the delivery of these medications because of several factors: their small size (portability); their low cost combined with higher efficiency when compared with conventional pneumatic nebulisation; and their simplicity in that no drug preparation is required so that it is difficult to contaminate the contents. ${ }^{5}$ However, the use of the inhaler alone can be associated with significant oropharyngeal

\footnotetext{
* Correspondence: Trudell Medical International, 725 Third Street, London, Ontario, Canada, N5V 5G4
}

Tel: +1 5194557060 ext. 2206 Fax: +1 5194556478 Email address: jmitchell@trudellmed.com 
deposition. ${ }^{6}$ Excellent patient co-ordination of inspiration with inhaler actuation is required for optimum drug delivery to the lungs, ${ }^{7.8}$ and this goal is frequently not achieved..$^{9,10}$ Valved holding chambers (VHCs) are add-on devices that interface with the actuator/mouthpiece of the pMDI, providing additional space for the aerosol plume to develop. They remove the ballistic component, thereby reducing the potential for systemic absorption, as well as retaining the aerosol until the patient can inhale. ${ }^{5}$ More importantly, they also promote inhaler actuation-inhalation co-ordination for both adults ${ }^{7}$ and children, ${ }^{11}$ and are therefore recommended in current clinical guidelines. ${ }^{1-4,12,13}$

While VHCs can improve targeting of pMDI-produced aerosols to the lower respiratory tract and can minimise systemic drug absorption by reducing oropharyngeal deposition, ${ }^{14}$ improper design as well as improper use can result in inconsistent medication delivery. In this review, these issues are discussed, using laboratory and clinical evidence to guide clinicians in their recommendations. The attributes of a welldesigned VHC are described together with considerations about how these devices should be used.

\section{Causes of inconsistent VHC performance}

Both device- and patient-related factors affect medication delivery from VHCs (see Table 1). The former are concerned with the function of the VHC itself, $5,6,15$ and are the focus of this review. The latter relate to the choice the clinician has to make in order to select the VHC that is most appropriate for the particular patient, considering the patient's capability and the device itself. ${ }^{15-17}$ Co-ordination of inhalation with pMDI actuation, though an important consideration ${ }^{17}$ that should be optimised, ${ }^{5}$ is not identified in the list of patient-related factors since $\mathrm{VHCs}$ are intended to overcome this cause of poor medication delivery. ${ }^{7.11}$

\section{Device-related factors \\ Electrostatic charge}

Electrostatic charge is a commonly-reported cause of inconsistent medication delivery from $\mathrm{VHCs} .{ }^{5}$ The electrostatic force can be thousands of times greater than the force of gravity for highly charged particles. ${ }^{18}$ Most aerosol particles carry electric charge, so that as well as affecting aerosol retention within the $\mathrm{VHC}{ }^{5}$ lung deposition may be affected. ${ }^{19,20}$ Removal of charge is desirable from the standpoint of achieving consistent deposition of medicationcontaining particles in the lower respiratory tract.

Electrostatic charges arise as the result of friction (triboelectrification) generated by the contact and separation of dissimilar materials - such as particles of the formulation themselves - as well as by interaction between particles and pMDI components that are electrical insulators. ${ }^{21}$ Aerosols emitted from pMDIs have an intrinsic electrostatic charge ${ }^{22}$ which has been characterised on a formulation-by-formulation basis. ${ }^{23-25}$ VHCs made from non-conducting polymers also acquire surface electrostatic charge during manufacture, packaging and storage. ${ }^{26}$ Such devices, if used without precautions to mitigate this phenomenon, can be associated with reduced output of medication. Barry and O'Callaghan were the first to examine this phenomenon systematically. They coated the inside of polycarbonate, non-conducting Nebuhaler VHCS (Astra Pharmaceuticals, now AstraZeneca) with an antistatic lining thereby eliminating charge. ${ }^{27}$ They found that the mass of pMDI-generated budesonide emitted as fine particles $<5 \mu \mathrm{m}$ aerodynamic diameter (likely to penetrate beyond the oropharynx to reach receptors in the lower respiratory tract) increased more than two-fold when charge was removed. Dewsbury et al. showed that electrostatic charge-associated Volumatic VHCs (GlaxoSmithKline (GSK)) may result in changes to the emitted particle size distribution. ${ }^{28}$

Table 1. Factors that may result in inconsistent medication delivery from VHCs.

\section{Device related}

Patient related

1. Choice of appropriate VHC and patient interface (mouthpiece or facemask) - infant, child, adult

2. Patient inhalation modality

3. Disease modality and severity - may affect ability to use a particular patient interface

3. Size (volume) of VHC in relation to patient breathing pattern more important for infants and small children

4. Facemask-to-face seal integrity - essential, especially for infants and small children

$\mathrm{VHC}=$ valved holding chamber 
When no charge was present, the fine particle fraction $(<6.8$ $\mu \mathrm{m}$ aerodynamic diameter) of salbutamol was close to $35 \%$, decreasing to just over $10 \%$ with the same devices that were highly charged. ${ }^{28}$

Surfactant is present in many formulations as an excipient to aid in operation of the pMDI. These compounds are either ionic species or contain polarisable molecules that allow electric charge to migrate to ground through the user. 'Priming' the interior surfaces of Nebuhaler and Volumatic VHCS with several actuations of medication before use by mild asthmatics to coat the interior surfaces with a layer of surfactant has been associated with increased whole lung deposition ranging between $41 \%$ and $45 \%{ }^{29}$ However, although apparently effective at increasing medication delivery, this practice is wasteful of medication. ${ }^{30}$ Furthermore, since some of the new hydrofluoroalkane (HFA)-based formulations do not contain surfactant, ${ }^{31}$ priming may lead to inconsistent results, ${ }^{32}$ and studies with these formulations are lacking.

Pre-washing VHCs with water containing a small amount of ionic detergent is an alternative approach, ${ }^{33,34}$ since detergents are actually surfactants and have the ability to spread onto a surface as a monolayer. ${ }^{35}$ Piérart et al. showed that washing in water containing cationic, anionic, or nonionic detergents with a detergent to water ratio ranging from $1: 125$ to $1: 10,000$ resulted in a higher emitted fine particle mass of salbutamol from Volumatic VHCs than from untreated devices. ${ }^{33}$ This finding is supported by improvement in clinical outcome associated with the delivery of salbutamol via detergent-coated VHCs to stable asthmatic patients; 1505 \pm 1335 mcg (mean \pm SD) salbutamol delivered by untreated Volumatic VHCs was observed to cause an improvement of $10 \%$ in $\mathrm{FEV}_{1}$, whereas if pre-washed $\mathrm{VHCs}$ were used the mass of salbutamol decreased to $430 \pm 732 \mathrm{mcg} \cdot{ }^{36}$ Piérart et al. indicated that the antistatic property of detergent lasts for at least four weeks. ${ }^{33}$ Hence, detergent-washing is recommended on a regular basis in at least one guideline. ${ }^{12}$

Rinsing add-on devices in clean water after being washed in detergent has been advocated in the US to avoid detergent-coated surfaces coming into direct contact with the patient and the possibility of contact dermatitis. ${ }^{37}$ However, Piérart et al. observed that Volumatic VHCs pretreated in this way retained significant residual electrostatic charge. Thus, salbutamol fine particle delivery was just over $36 \%$ of the label claim emitted mass/actuation when detergent-treated and rinsed, increasing to close to $50 \%$ for detergent-treated but non-rinsed devices. ${ }^{33}$ Berg showed that it can take as many as 40 actuations of medication after cleaning for charged Nebuhaler VHCs to become coated with sufficient medication from a formulation containing surfactant to achieve consistent and comparable emitted mass/actuation to that from an uncharged $\mathrm{VHC}{ }^{38}$ Rinsing should therefore be avoided in favour of drip-drying. Toweling dry-washed VHCs should also not be undertaken, ${ }^{39}$ since charge may be imparted by this process. ${ }^{34}$

VHCS manufactured from good electrical-conducting materials, such as steel or aluminum, are effective at eliminating electrostatic charge..$^{40,41}$ For instance, Janssens et al. collected pMDI-delivered budesonide at a filter located between the VHC and the patient using stainless steel NebuChamber VHCs (AstraZeneca). ${ }^{42}$ Emitted mass/actuation (mean \pm SD) was 41.7 $\pm 10.1 \%$ nominal dose for $1-4$ year olds and $50.3 \pm 9.2 \%$ for 5-8 year olds. These values were significantly higher than $26.0 \pm 4.0 \%$ for $1-4$ year olds via the Babyhaler (GSK) or the $19.4 \pm 7.2 \%$ for $5-8$ year olds using Volumatic VHCs. However, with a metallic $\mathrm{VHC}$, the health care provider cannot see the aerosol forming within the VHC on inhaler actuation and subsequently disappearing on inhalation. This is an important source of feedback when delivering medication to infants or small children. ${ }^{43}$ Devices made from transparent, chargedissipative materials overcome this limitation and are therefore more patient-friendly, and they have been shown in laboratory ${ }^{44,45}$ and early clinical studies to be effective. ${ }^{46}$

The ability to eliminate electrostatic charge is important when patients delay inhalation of their medication, as frequently occurs. ${ }^{9,47}$ In a study with several untreated or water-rinsed non-conducting $\mathrm{VHCS}$, Rau et al. showed that delivery of salbutamol could be significantly compromised when a delay as short as 2 seconds occurred between pMDI actuation and the onset of simulated inhalation. In contrast, VHCs manufactured with either conducting (aluminium) or charge-dissipative transparent polymer provided consistent fine particle delivery (see Table 2). ${ }^{48} \mathrm{~A}$ simulated 2-second delay for laboratory testing is considered representative of likely use by an unco-ordinated patient. ${ }^{49}$

Despite laboratory studies showing that electrostatic charge has a deleterious impact on VHC performance, the clinical evidence is less clear. Anhøj et al. observed that the charge associated with two non-conducting $\mathrm{VHCs}$, washed but rinsed afterwards, reduced lung deposition in children aged from 7 to 12 years by a factor of more than two-fold. ${ }^{50}$ This behaviour was associated with significant decreases in plasma salbutamol concentrations. In contrast, Dompeling et al. reported that differences in bronchodilating effect based on measures of peak expiratory flow (PEF) were insignificant in children given salbutamol using two pre-washed, nonconducting VHCs (Volumatic and AeroChamber), compared with responses associated with electrically-conducting NebuChamber VHCs. ${ }^{51}$ However, the children tested had excellent inhaler technique and their PEFs may have already reached the plateau at the high end of the dose-response curve. Dubus et al. also found little difference in clinical 
Table 2. Fine particle mass $<4.7 \mu \mathrm{m}$ aerodynamic diameter for salbutamol (mean \pm SD) delivered via non-conducting and non-electrostatic VHCs with delay of $2 \mathrm{~s}$ between pMDI actuation and onset of sampling (data from ref. 48 used by permission).

\begin{tabular}{|c|c|c|c|}
\hline \multirow[b]{2}{*}{ VHC } & \multirow[b]{2}{*}{ Type } & \multicolumn{2}{|c|}{ Fine particle mass with $2 \mathrm{~s}$ delay $(\mu \mathrm{g})$} \\
\hline & & $\begin{array}{l}\text { no pre-treatment } \\
\text { (out of package) }\end{array}$ & $\begin{array}{l}\text { pre-washed } \\
\text { and rinsed }\end{array}$ \\
\hline AeroChamber Max ${ }^{\circledast}$ & charge dissipative polymer & $23.8 \pm 4.8$ & $21.5 \pm 3.2$ \\
\hline Vortex ${ }^{\oplus}$ & conducting metal (aluminium) & $16.2 \pm 1.7$ & $15.5 \pm 2.0$ \\
\hline OptiChamber ${ }^{\circledast}$ Advantage & non-conducting polymer & $2.6 \pm 1.2$ & $6.7 \pm 2.3$ \\
\hline ProChamber TM & non-conducting polymer & $1.6 \pm 0.4$ & $5.1 \pm 2.5$ \\
\hline Breathrite $^{\mathrm{TM}}$ & non-conducting polymer & $2.0 \pm 0.9$ & $3.2 \pm 1.8$ \\
\hline PocketChamber ${ }^{\circledast}$ & non-conducting polymer & $3.4 \pm 1.6$ & $1.7 \pm 1.6$ \\
\hline$A C E^{\circledast}$ & non-conducting polymer & $4.5 \pm 0.9$ & $5.4 \pm 2.9$ \\
\hline
\end{tabular}

$\mathrm{VHC}=$ valved holding chamber

Figure 1. Options for pre-treatment and use for VHCs to avoid inconsistent delivery of medication due to the presence of electrostatic charge.

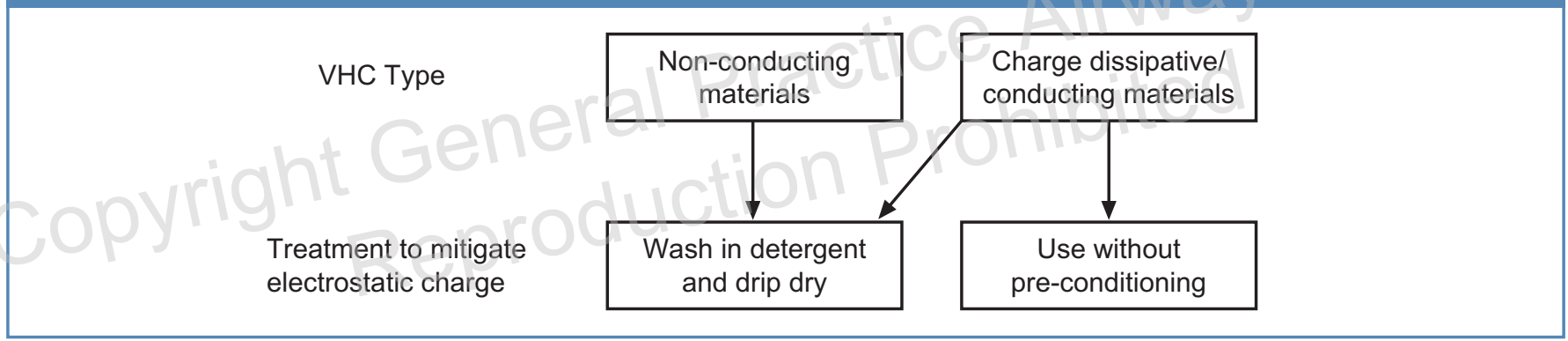

outcome measures (specific airway resistance and forced expiratory volume in one second $\left[\mathrm{FEV}_{1}\right]$ ) using nonconducting or conducting VHCs when treating moderately asthmatic children with salbutamol. ${ }^{52}$ However, they too acknowledged that their patients were at the plateau of the dose-response curve. They further observed that methacholine challenge, used to assess airway responsiveness, does not mirror an asthma attack. In reviewing the clinical evidence, Le Souëf stated that the increase in performance associated with detergent pretreatment of spacers (VHCs) manufactured from nonconducting materials is almost certainly important for inhaled corticosteroids. ${ }^{53}$ Clinicians should therefore be aware of ways to minimise or avoid electrostatic charge when prescribing VHCS (Figure 1), given the possibility that under-dosing for some formulations may occur if significant charge is present.

\section{VHC valve function}

The valves that operate on inhalation and exhalation must function effectively over the entire pressure range likely to be encountered with the use of the $\mathrm{VHC}{ }^{6,54}$ This requirement is unlikely to be a problem for adults, since the pressure required to operate valves of most add-on devices is less than 100 to $300 \mathrm{~Pa}^{54}$ However, it may become an issue for neonates or infants if the valves are stuck closed. The literature relating to such events is scarce, although in a study of three types of VHC intended for paediatric use, in which salbutamol and beclomethasone dipropionate delivery was examined with each device connected to a breathing simulator, neither drug was obtained from two of the devices due to failure of their inhalation valves to open when mimicking infant use $(50 \mathrm{ml}$ tidal volume, inspiratory/expiratory ratio 40/60, 30 breaths/min). ${ }^{55}$ However, the valves operated normally at higher tidal volumes. The ability to observe valve movement in response to patient breathing is a significant benefit in confirming that these components are functioning correctly. ${ }^{43,56}$

\section{VHC size (volume)}

Chamber volume can also affect medication delivery, ${ }^{57}$ but VHCs between 150 to $250 \mathrm{ml}$ capacity are for the most part 
as effective as $750 \mathrm{ml}$ devices. ${ }^{14,58-60}$ Fewer inhalations are required to empty smaller devices, which is advantageous for infants and small children. ${ }^{43}$ Since they are more compact, there may be a benefit for all patients in terms of compliance $^{16,43}$ - an important consideration for older children who may be embarrassed to use accessory devices. ${ }^{61}$

If a facemask is used, it should have a dead volume that is as small as possible when applied with the minimum of force to seal to the face, ${ }^{62}$ since drug delivery is reduced by the proportion of dead space to tidal volume. ${ }^{26}$ This is particularly significant with infants ${ }^{63}$ who might have low tidal volume combined with high respiratory rate due to cardiopulmonary disease or metabolic acidosis. ${ }^{64}$ The magnitude of dead volume is closely influenced by the facemask/NHC design, as well as by the force applied when fitting the facemask. ${ }^{62}$ For example, the Babyhaler VHC has a fixed dead space close to $40 \mathrm{ml},{ }^{65}$ which is a significant fraction of the tidal volume for this class of patients. ${ }^{50}$ Facemasks incorporating the exhalation valve, and ideally shaped for the particular age category of the user, ${ }^{66}$ are intended to minimise dead volume in use. ${ }^{67}$

\section{Facemask-to-face seal integrity}

The delivery of medication from a $\mathrm{VHC}$ with a mouthpiece is assured once the user seals their lips around the mouthpiece and inhales. In contrast, aerosol delivery via a facemask will be compromised if an effective mask-to-face seal is not achieved. ${ }^{68,69}$ This is because, once the aerosol plume has expanded following pMDI actuation, there is no additional pressure to direct the aerosol flow to the patient. Infants, in particular, may achieve insufficient inhalation flow to do much more than entrain ambient air via the leak path. ${ }^{66,70,71}$ They may also struggle against treatment, thereby enhancing the possibility of leakage. ${ }^{72}$

Esposito-Festen et al., using an upper airway obligate nasalbreathing infant model $(100 \mathrm{ml}$ tidal volume) investigated the relationship between leak magnitude and drug delivery by creating circular apertures of known area in a round-shaped resuscitation facemask (GaleMed Corp., Taipei, Taiwan). ${ }^{73}$ They observed measurable decreases in emitted drug mass with a leakage area of only $0.05 \mathrm{~cm}^{2}$. Almost no aerosol was collected when this area was ten times greater. Janssens et al. confirmed these findings in wheezy infants by observing that dose delivery was more effective using the Babyhaler VHC - which has an inwardly curved lip compared with the straight-edged facemask of the NebuChamber VHC that was more sensitive to leakages caused by face movements. ${ }^{70}$ Esposito-Festen et al. arrived at a similar conclusion in a trial involving 24 children being treated for recurrent wheeze; they compared collected drug mass on a filter placed between the VHC and facemask. ${ }^{74}$ Filter-collected mass (mean \pm SD) was $39 \pm 14 \%$ of the nominal dose exinhaler for the facemask supplied with the NebuChamber VHC, increasing to $47 \pm 12 \%$ when a round facemask with inwardcurving lip (GaleMed) was substituted.

Three considerations follow from these observations. Firstly, the use of a flexible facemask that conforms to the

\section{Table 3. VHC characteristics that promote consistent medication delivery.}

Compact (intermediate) size to minimise number of inhalations to empty chamber (paediatric use) $)^{26,43}$ and allow improved portability (all users) ${ }^{16}$

Electrically conducting or non-electrostatic (anti-static) materials in construction ${ }^{26}$ (transparent materials have the advantage that they allow visualisation of the aerosol following inhaler actuation)

Responsive inhalation (and exhalation) valves ${ }^{43,55}$

Capability to observe valve movement (especially for VHCs with facemask), including the means to co-ordinate inhaler actuation with inhalation ${ }^{43}$

Ability to ensure a good facemask seal to face ${ }^{70}$

Designs that are specific for infant, child or adult use, specifically to minimise dead volume in facemask and ensure responsive valve operation ${ }^{66}$ Facemask with minimal dead volume and comfortable fit with the minimum of applied force to achieve a seal to the face ${ }^{62,64}$

Exhalation valve in facemask to decrease re-breathing ${ }^{11}$ and offer low resistance to exhaled flow ${ }^{43}$

Clear instructions for washing (cleaning) both before use and in use at specified intervals ${ }^{12}$ (particularly for devices manufactured from nonconducting materials)

VHC = valved holding chamber 
contours of the patient's face is less prone to leakage and will have reduced dead volume when fitted properly, in contrast with more rigid designs. ${ }^{62,75}$ Secondly, care should be exercised to ensure that leakage from poor connections with detachable facemasks does not occur. Finally, VHCs in which the movement of both inhalation and exhalation valves in response to the breathing cycle of the patient is visible, provide the healthcare professional and caregiver with the reassurance that an effective seal has been achieved between facemask and face. ${ }^{43}$

\section{Points to consider when selecting a VHC}

Based on the above, there are, therefore, various VHC characteristics which promote consistent medication delivery - see Table 3. Those that relate to the device form the basis of this review. However, patient-related factors are also an important consideration. The choice of appropriate interface is largely age-related, with an appropriately sized facemask the recommended choice for infants and younger children not yet capable of coping with a mouthpiece. ${ }^{2,4}$ However, a facemask may also be appropriate for adults, especially the elderly who may have cognitive impairment. ${ }^{7,39,76}$

The way in which the patient inhales (the inhalation modality) is another factor that affects aerosol deposition. Ernst has reported that for efficient use of pMDIs, the user should inhale slowly and continuously followed by a breathhold of at least 10 seconds $^{77}$ thereby allowing the aerosol to penetrate deeply into the lungs. ${ }^{78}$ Guidance on the GINA website for the use of the AeroChamber VHC with mouthpiece is based on this inhalation modality, but both slow inhalation and tidal breathing modalities are provided for the Volumatic VHC with mouthpiece. ${ }^{79}$ Younger children using a facemask are able to breathe tidally, and indeed this is likely to be the optimal modality for infants. ${ }^{66}$ Until recently, no study with children has systematically examined issues such as the optimal time of inhalation and whether the patient should use tidal breathing or the long slow inhalation technique when using a VHC ${ }^{53}$ However, Roller et al. have recently reported that for inhalation of a formulation containing extrafine beclomethasone dipropionate with mass median aerodynamic diameter (MMAD ) close to $1.1 \mu \mathrm{m}$ in a cohort of 24 children aged from 5-17 years, slow inhalation to vital capacity followed by a breath-hold of at least 5 seconds showed improved lung deposition compared with tidal breathing. ${ }^{80}$ These subjects used a small volume VHC (AeroChamber Plus with mouthpiece) and deposition was assessed by $\gamma$-scintigraphy. Further studies are needed to see if similar results are obtained with the majority of formulations that contain larger particles, with MMADs in the range 2-4 $\mu \mathrm{m}$.

The influence of disease on VHC use has not been systematically studied, probably because of the difficulties in designing studies with sufficient power to come to conclusions. However, clinicians should be aware of conditions that might affect the ability of the patient to use a particular interface (for example - cognitive decline in the elderly) and should adapt accordingly. In addition, clinical guidelines relating to asthma advise repeated observation of patient inhaler technique as well as recommending titration to the minimum dose of medication that is effective. ${ }^{2,4}$

\section{Conflict of interest declaration}

Both authors are employees of Trudell Medical International, the manufacturer of the Aerochamber brand Valved Holding Chambers.

\section{References}

1. Becker $A$, Lemière $C$, Bérubé $D$, et al. on behalf of the Asthma Guidelines Working Group of the Canadian Network for Asthma Care and the Canadian Thoracic Society. 2005. Summary of recommendations from the Canadian Asthma Consensus Guidelines, 2003, and Canadian Pediatric Asthma Consensus Guidelines. CMAJ 2003;173(6 suppl.):S1-S56. Available at: URL http://www.canadianmedicaljournal.ca.

2. Global Initiative for Asthma (GINA). Global Strategy for Asthma Management and prevention. 2006. Available at: URL http://www.ginasthma.com.

3. O'Donnell DE, Aaron S, Bourbeau J, et al. State of the art compendium: Canadian Thoracic Society recommendations for the management of chronic obstructive pulmonary disease. Can Respir J 2004;11(Suppl.B):7B-59B. Available at: URL http://www.copdguidelines.ca.

4. Global Strategy for Diagnosis, Management, and Prevention of Chronic Obstructive Lung Disease (COPD). 2006. Available at: URL http://www.goldcopd.com.

5. Dolovich M., Macintyre NR, Anderson PJ, et al. Consensus statement: Aerosols and delivery devices. Respir Care 2000;45(6):589-96.

6. Fink JB. Metered-dose inhalers, dry powder inhalers, and transitions. Respir Care 2000;45(6):623-35

7. Dolovich MB, Ahrens RC, Hess DR, et al. Device selection and outcomes of aerosol therapy: Evidence-based guidelines. Chest 2005;127(1):335-71.

8. Anderson PJ. Delivery options and devices for aerosolized therapeutics. Chest 2001;120(Suppl):89S-93S.

9. Melani AS, Zancetta D, Barbato N, et al. Inhalation technique and variables associated with misuse of conventional metered-dose inhalers and newer dry powder inhalers in experienced adults. Ann Allergy Asthma Immunol 2004;93(5):439-46.

10. Barnes P, Virchow JC, Sanchis J, Welte T, Pedersen S. Asthma management: Important issues. Eur Respir Rev 2005;14(Review 97):147-51.

11. Rubin BK, Fink JB. Optimizing aerosol delivery by pressurized metered-dose inhaler. Respir Care 2005;50(9):1191-200.

12. British Thoracic Society/Scottish Intercollegiate Guidance Network (SIGN). 2005. British guideline on the management of asthma. Publication 63. Available at URL http://www.sign.ac.uk.

13. UK National Institute for Clinical Excellence (NICE). 2000. Guidance on the use of inhaler systems (devices) in children under the age of 5 with chronic asthma. Technology appraisal guidance No.10. Available at URL http://www.nice.org.uk.

14. Corr D, Dolovich M, McCormack D, Ruffin R, Obminski G, Newhouse M Design and characteristics of a portable breath actuated, particle size selective medical aerosol inhaler. J Aerosol Sci 1982;13(1):1-7.

15. Geller DE. Comparing clinical features of the nebulizer, metered-dose inhaler, and dry powder inhaler. Respir Care 2005;50(10):1313-22.

16. Cheng NG, Browne GJ, Lam LT, Yeah R, Oomens M. Spacer compliance after discharge following a mid to moderate asthma attack. Arch Dis Child 2002;87: 302-05. 
17. Chapman KR, Voshaar TH, Virchow JC. Inhaler choice in primary practice. Eur Respir Rev 2005; 14:117-22.

18. Hinds WC. Aerosol Technology. New York: John Wiley \& Sons; 1982:284-314.

19. Melandri C, Tarroni G, Prodi V, De Zaiacono T, Formigiani M, Lombardi CC. Deposition of charged particles in the human airways. J Aerosol Sci 1983; 14(5):657-69.

20. Bailey AG. The inhalation and deposition of charged particles within the human lung. J Electrostat 1997;42:25-32.

21. Noakes T. Electrostatics: The next issue for inhaled medications. Drug Delivery Technol 2004; 4:1-5.

22. Kwok PCL, Chan H-K. Electrostatic charge in pharmaceutical systems. Encyclopedia of Pharmaceutical. Technology. 2nd Edition. New York: Taylor \& Francis, 2005. p.1-14.

23. Peart J, Magyar C, Byron PR. Aerosol electrostatics: Metered-dose inhalers (MDIs). Dalby RN, Byron PR, Farr SJ, eds. Respiratory Drug Delivery-VI. Buffalo Grove, IL. USA: Interpharm Press, 1998. p.227-33.

24. Glover W, Chan H-K. Electrostatic charge characterization of pharmaceutical aerosols using electrical low-pressure impaction (ELPI). J Aerosol Sci 2004; 35(6):755-64.

25. Keil JC, Kotian R, Peart J. Using and interpreting aerosol electrostatic data from the electrical low pressure impactor. Dalby RN, Byron PR, Peart J, Suman JD, Farr SJ, eds. Respiratory Drug Delivery-X. River Grove. IL. USA: Davis Horwood International Publishing, 2006. p.267-77.

26. Bisgaard H, Anhøj J, Wildhaber JH. Spacer devices. In: Bisgaard H, O'Callaghan C, Smaldone GC, eds. Drug Delivery to the Lung. New York, NY: Marcel Dekker Inc., 2002. p.389-420.

27. Barry PW, O'Callaghan C. The effect of delay, multiple actuations and spacer static charge on the in vitro delivery of budesonide from the Nebuhaler. $\mathrm{Br}$ J Clin Pharmacol 1995;40:76-8.

28. Dewsbury NJ, Kenyon CJ, Newman SP. The effect of handling techniques on electrostatic charge on spacer devices: A correlation with in vitro particle size analysis. Int J Pharm 1996;137:261-4.

29. Kenyon CJ, Thorsson L, Borgström L, Newman SP. The effects of static charge in spacer devices on glucocorticosteroid aerosol deposition in asthmatic patients. Eur Respir J 1998;11:606-10.

30. Rau JL. Practical problems with aerosol therapy in COPD. Respir Care 2006; 51(2):158-72.

31. Peart J, Kulphaisal P, Orban JC. Relevance of electrostatics in respiratory drug delivery. Business Briefing: Pharmagenerics. 2003. Available at URL: http://www.touchbriefings.com/pdf/890/PT04_peart.pdf.

32. Barry PW. Ph.D Thesis. University of Leicester, UK. 1999.

33. Piérart F, Wildhaber JH, Vrancken I, Devadason SG, Le Souëf PN. Washing plastic spacers in household detergent reduces electrostatic charge and greatly improves delivery. Eur Respir J 1999;13:673-8.

34. Wildhaber JH, Devadason SG, Hayden MJ, et al. Electrostatic charge on a plastic spacer device influences the delivery of salbutamol. Eur Respir J 1996;9:1943-6.

35. Shaw DJ. Introduction to colloid and surface chemistry. 4th Edition. Oxford, UK: Butterworth-Heinemann, 1999.

36. Wildhaber JH, Waterer GW, Hall GL, Summers QA. Reducing electrostatic charge on spacer devices and bronchodilator response. $\mathrm{Br} J$ Clin Pharmacol 2000;50:277-80.

37. Allergy \& Asthma Network Mothers of Asthmatics (AANMA). Maximize the mist: Keep inhalers clean, primed and ready. Allergy and Asthma Today 2005; Winter:17-20. Available at URL: http://aanma.org/pdf/MaximizeMist.pdf.

38. Berg E. In vitro properties of pressurized metered dose inhalers with and without spacer devices. J Aerosol Med 1995;8(Suppl.3):S3-S11.

39. Boulet L-P, Becker A, Bérubé D, Beveridge R, Ernst P. Canadian asthma consensus report, 1999. CMAJ 1999; 161(11Suppl.): S44-S50. Available at: http://www.canadianmedicaljournal.ca.
40. Bisgaard H. A metal aerosol holding chamber devised for young children with asthma. Eur Respir J 1995;8:856-60.

41. Bisgaard H, Anhøj J, Klug B, Berg E. A non-electrostatic spacer for aerosol delivery. Arch Dis Child 1995;73:226-30.

42. Janssens HM, Devadason SG, Hop WCJ, Le Souëf PN, De Jongste JC, Tiddens HAWM. Variability of aerosol delivery via spacer devices in young asthmatic children in daily life. Eur Respir J 1999;13:787-91.

43. Dolovich MB. In my opinion - Interview with the expert. Pediatr Asthma Allergy Immunol 2004;17(4):292-300.

44. Mitchell JP, Morton RW, Schmidt JN, Snyder S., Doyle CC, Nagel MW. Overcoming electrostatic charge retention in a new valved holding chamber (VHC): In vitro performance comparison with current devices. Dalby RN, Byron PR, Peart J, Suman JD, Farr SJ, eds. Respiratory Drug Delivery IX. Oak Brook, IL, USA: Davis Healthcare International Publishing, 2004. p.705-707.

45. Coppolo DP, Mitchell J, Nagel MW. Levalbuterol aerosol delivery with a nonelectrostatic versus a non-conducting valved holding chamber. Respir Care 2006;51(5):511-14.

46. Asmus MJ, Hochhaus G, Tang Y, Spencer LT, Chesrown SE, Hendeles L. Impact of new anti-static valved holding chamber on airway delivery of inhaled fluticasone propionate in asthmatic children. Am J Respir Crit Care Med 2004;169:A150.

47. McFadden ER Jr. Improper patient techniques with metered dose inhalers: Clinical consequences and solutions to misuse. J Allergy Clin Immunol 1995; 96(2):278-83.

48. Rau JL, Coppolo DP, Nagel MW, et al. The importance of non-electrostatic materials in holding chambers for delivery of hydrofluoroalkane albuterol. Respir Care 2006;51(5):503-10.

49. Dolovich MB, Mitchell JP. Canadian Standards Association standard CAN/CSA/Z264.1-02:2002: A new voluntary standard for spacers and holding chambers used with pressurized metered-dose inhalers. Can Respir J 2004; 11(7):489-95.

50. Anhøj J, Bisgaard H, Lipworth BJ. Effect of electrostatic charge in plastic spacers on the lung delivery of HFA-salbutamol in children. Br J Clin Pharmacol 1999; 47:333-6.

51. Dompeling E, Oudesluys-Murphy AM, et al. Randomised controlled study of clinical efficacy of spacer therapy in asthma with regard to electrostatic charge. Arch Dis Child 2001;84:178-82.

52. Dubus JC, Guillot C, Badier M. Electrostatic charge on spacer devices and salbutamol response in young children. Int J Pharm 2003;261:159-64.

53. Le Souëf PM. Drug delivery. M ed J Aust 2002;177(6 Suppl):S69-S71.

54. Bisgaard H. Delivery of inhaled medication to children. J Asthma 1997;34(6): 443-67.

55. Mitchell JP, Nagel MW. In vitro performance testing of three small volume valved holding chambers under conditions that correspond with use by infants and small children. J Aerosol Med 1997;10(4):341-9.

56. Crompton GK, Barnes PJ, Broeders M, et al. The need to improve inhalation technique in Europe: A report from the Aerosol Drug Management Improvement Team. Respir Med 2006;100:1479-94.

57. Barry PW, O'Callaghan C. The optimum size and shape of spacer devices for inhalational therapy. J Aerosol Med 1995;8(3):303-05.

58. Mitchell JP, Nagel MW, Rau JL. Performance of large volume versus small volume holding chambers with chlorofluorocarbon-albuterol and hydrofluoroalkane albuterol sulfate. Respir Care 1999;44(1):38-44.

59. Nagel MW, Wiersema KJ, Bates SL, Mitchell JP. Performance of large and small volume valved holding chambers with a new combination long-term bronchodilator/anti-inflammatory formulation delivered by pressurized metered dose inhaler. J Aerosol Med 2002;15(4):427-33.

60. Dolovich M. Lung dose, distribution, and clinical response to therapeutic aerosols. Aerosol Sci Technol 1993;18(3):230-40.

61. Gray S. Asthma inhaler devices. 2006. UK National Library of Health. Available at URL: http://www.library.nhs.uk/respiratory/. 
62. Shah SA, Berlinski A and Rubin BK. Force-dependent static dead space of face masks used with holding chambers. Respir Care 2006;51(2):140-4.

63. Cole $\mathrm{CH}$. Special problems in aerosol delivery: Neonatal and pediatric considerations. Respir Care 2000;45(6):646-51.

64. Amirav, I. Infant aerosol holding chamber face masks: Not all are born equal! Respir Care 2006;51(2):123-5.

65. Kraemer R, Frey U, Sommer CW, Russi E. Short-term effect of albuterol, delivered via a new auxiliary device in wheezy infants. Am Rev Respir Dis 1991; 144:347-51

66. Everard ML. Inhalation therapy for infants. Adv Drug Deliv Rev 2003;55:869-78.

67. Morton RW, Mitchell JP. Design of Facemasks for Delivery of Aerosol-Based Medication via Pressurized Metered Dose Inhaler (pMDI) with Valved Holding Chamber (VHC): Key Issues that Affect Performance. J Aerosol Med 2007; 20(Suppl.1):S29-S45

68. Amirav I. Aerosol therapy. Ital J Pediatr 2004;30:147-56.

69. Everard ML, Clark AR, Milner AD. Drug delivery from holding chambers with attached facemask. Arch Dis Child 1992;67:580-5.

70. Amirav I, Newhouse MT. Aerosol therapy with valved holding chambers in young children: Importance of the facemask seal. Pediatrics 2001;108:389-94.

71. Rubin BK, Fink JB. Optimizing aerosol delivery by pressurized metered-dose inhalers. Respir Care 2005;50(9):1191-200.

72. Janssens HM, Heijnen EMEW, de Jong VM, et al. Aerosol delivery from spacers in wheezy infants: A daily life study. Eur Respir J 2000;16:850-6.
73. Esposito-Festen JE, Ates B, Van Vliet FLM, Verbraak AFM, de Jongste JC, Tiddens HAWM. Effect of a facemask leak on aerosol delivery from a pMDIspacer system. J Aerosol Med 2004;17:1-6

74. Esposito-Festen J, Ates B, Van Vliet F, Hop W, Tiddens H. Aerosol delivery to young children by pMDI-spacer: Is facemask design important? Pediatr Allergy Immunol 2005; 16:348-53.

75. Amirav I, Mansour Y, Mandelberg A, Bar llan I, Newhouse MT. Redesigned facemask improves "real life" aerosol delivery for Nebuchamber. Pediatr Pulmonol 2004;37:172-7

76. Nair LG, Diamond R Falcone G, Thakore S Fine JM. Efficacy of mask spacer with metered dose inhaler in the frail elderly. Chest 1995;108(Suppl):216S (abstract).

77. Ernst P. Inhaled drug delivery: A practical guide to prescribing inhaler devices. Can Respir J 1998;5(3):180-3.

78. Laube BL, Norman PS, Adams GK. The effect of aerosol distribution on airway responsiveness to inhaled methacholine in patients with asthma. J Allergy Clin Immunol 1992;89:510-18.

79. Global Initiative for Asthma (GINA). Instructions for inhaler and spacer use. 2006. Available at: URL http://www.ginasthma.com.

80. Roller CM, Zhang G, Troedson RG, Leach CL, LeSouëf PN. Spacer inhalation technique and deposition of extrafine aerosol in asthmatic children. Eur Respir 2007;29:299-306

Available online at http://w w w.thepcrj.org 